\title{
A Prospective Study to Evaluate Prescription Pattern of Second Line Antiretroviral Therapy Given to HIV Patients
}

\author{
Jigar P. Modi ${ }^{1}$, Amita Kubavat ${ }^{2}$, Shailesh Mundhava ${ }^{3}$, Usha Lalwani ${ }^{4}$ \\ 'Tutor, B J Medical College, Pharmacology Department, Ahmedabad, Gujarat, INDIA. \\ ${ }^{2}$ Associate Professor, PDU govt. medical college, Pharmacology Department, Govt. Medical College, Rajkot, Gujarat, INDIA. \\ ${ }^{3}$ Assistant Professor, PDU govt. medical college, Pharmacology Department, Govt. Medical College, Rajkot, Gujarat, INDIA. \\ ${ }^{4}$ Tutor, Department of Pharmacology, GMERS medical college and hospital, Sola, Ahmedabad, Gujarat, INDIA.
}

\begin{abstract}
Aims: To evaluate prescription pattern during second line Antiretroviral Therapy (ART) at tertiary care hospital. Despite a very large number of patient being covered under ART, there are limited data in Indian population regarding second line ART. Therefore, the present study was undertaken. Methods: After consultation with physician of ART plus centre, patient was interviewed and details of the patient's case record was obtained. At each encounter on every $30^{\text {th }}$ day patient's investigations, opportunistic infections, adherence level, associated medical conditions, second line ART and other drug prescription was recorded in preformed case record form for the study. Results: Out of 70 patients, 16 patients [22.86\%] had history of $2^{\text {nd }}$ line ART from Private ART clinics and 54 patients [77.14\%] were transferred from other government ART centers. Mean time to switching from first line to second line ART was $3.67 \pm 2.29$ years in 63 patients. Most common ART regimen prescribed at the initiation of second line ART was tenofovir+ lamivudine+ atazanavir /ritonavir in 45 patients [64.29\%] with 264 encounters. Most common opportunistic infection was ARI [recur-
\end{abstract}

rent respiratory infection] with $28.84 \%$ incidence. Conclusion: Irrational practice by private hospitals limits treatment options with increasing the chances of drug resistance. On the other hand NACO sponsored second line ART was given with a proper treatment protocol causes good compliance in patients.

Key words: Human Immunodeficiency Virus, Antiretroviral Therapy, Prescription pattern, Adherence, NACO.

\section{Correspondence:}

Dr. Usha Lalwani, Department of Pharmacology, GMERS medical college and hospital, Sola, Ahmedabad, Gujarat, INDIA.

Phone: +919687285342

Email: ushalalwani89@gmail.com

DOI: 10.5530/jyp.2018.10.26

\section{INTRODUCTION}

Human Immunodeficiency Virus [HIV] infection has been a growing challenge worldwide for the past three and half decades. Since the first cases of acquired immunodeficiency syndrome [AIDS] were reported in 1981, infection with human immunodeficiency virus [HIV] has grown to pandemic proportions. ${ }^{1}$ According to the World Health Organization [WHO] there were approximately 35 million people worldwide living with HIV/AIDS in 2013. India has the third largest HIV epidemic in the world. HIV prevalence in India was an estimated 0.3 percent.

It is estimated that around 2.1 million people are currently living with HIV in India. ${ }^{2}$

The advent of highly active Antiretroviral therapy [HAART] has been a boon for human immunodeficiency virus [HIV] infected patients by reducing morbidity and extending lifespan. ${ }^{3}$ However, with increasing exposure to first line ART the risk of viral resistance and subsequent treatment failure has become more important, and switching to second-line regimens is increasingly needed. WHO estimates that the average switch rate from first to second line ART is $2-3 \%$ per year for adults. ${ }^{4}$

In order to expand the access to second line treatment, 37 "ART Plus" centers started and capacitated to provide second line/alternative first line treatment to eligible Patients. Till Sept.2014, 10,223 patients were received second line ART drugs from ART Plus Centers.

Prescription of multiple drugs are common in HIV positive individuals particularly after initiation of ART. Therefore, they are at a higher risk of drug interactions and adverse drug reactions. The principal aim of drug prescription research is to facilitate rational use of drugs in populations.
So monitoring of prescription pattern can be helpful to change or design future treatment protocols. Despite a very large number of patients being covered under ART, there are limited data in Indian population regarding second line ART. Therefore, the present study was undertaken to evaluate prescription pattern during second line ART at tertiary care hospital.

\section{METHOD}

Patients selected on the basis of inclusion and exclusion criteria were explained in detail about this study. Written informed consent of all the patients was obtained before enrollment into the study as participant. Patients were explained about the nature of HIV infection, importance of ART and adherence to ART during treatment.

In our ART plus centre antiretroviral therapy is usually provided for 30 days. The patient had to come after 30 days of last visit to refill antiretroviral therapy for next month. At each encounter patient has to consult physician in charge of the ART plus centre. Line of management, ART and other drug prescription was carried out by physician. Patient coming for follow up before monthly interval either because of adverse events or any other health related condition; follow up data was recorded for that. After consultation with physician of ART plus centre, patient was interviewed and details of patient's case record was obtained. At each encounter opportunistic infections, adherence level, associated medical conditions, second line ART and other drug prescription was recorded in preformed case record form for the study.

Statistical analysis 
Recorded data was analyzed by Microsoft Office Excel 2013 and software Graphpad prism 6.

Normal distribution of study data was analyzed using D'Agostino - pearson omnibus test.

\section{RESULTS}

In this study, based on inclusion and exclusion criteria, total of $70 \mathrm{pa}-$ tients were enrolled during the study period. Out of these 70 enrolled patients, 63 patients were completed six months of second line ART. A 7 patients did not complete six months of treatment at ART plus center because either they were died or lost to follow up before completion of 6 months second line ART. Hence, further analysis was carried out on these 63 patients' data.

Out of 70 patients, majority of the patients were male [75.71\%] as compared to female [24.29\%]. Most common age group [50\%] was 37-55 years. Mean age of patients was $38.58 \pm 9.20$ [mean \pm SD] years. Age and gender and distribution of the study participants were summarized in Figure 1. Out of 70 patients, 8 were smoker while 9 and 4 patients had habit of consume tobacco chewing and alcohol respectively.

A total of $44.29 \%$ patients suffering from AIDS were educated up to primary level while $14.29 \%$ patients were illiterate (Table 1) and marital status of patients of the study participants were summarized in Table 2. Distribution of the patients based on duration of first line ART was summarized in Table 3. Total of 54 patients had started second line ART from government ART plus center. While 16 patients [22.86\%] had started their second line ART in private and then they were either referred or transferred to government ART plus center. Distribution of the patients based on duration of second line ART was summarized in Table 4. Treatment substitutions [within second line ART regimens] and treatment hold and restart summarized in Table 5 and 6 respectively. Distribution of patients according level of adherence to second line art presented in Table 7.

Out of 70 patients, 42 patients [71.42\%] were initiated and 20 patients [28.57\%] were not initiated co-trimoxazole prophylaxis at start of ART. In spite of starting co-trimoxazole prophylaxis at start of treatment there were 42 [80.76\%] incidences of opportunistic infections (Table 8). Most common opportunistic infection recorded was ARI [recurrent respiratory infection] with $28.84 \%$.

\section{DISCUSSION}

In this study, among 70 enrolled patients having HIV, majority [92.86\%] were falling in age group of $18-55$ years [Figure 1]. This is in concordance with other study performed in India which showed $89.3 \%$ of study population was of age group 20-50 years. ${ }^{5} \mathrm{HIV} / \mathrm{AIDS}$ is a disease of reproductive age, as evident from the HIV prevalence being higher [86\%] in the age group of 15-49 years. ${ }^{4}$ In this study mean age of study population was $38.58 \pm 9.20$ [mean $\pm \mathrm{SD}$ ] years that is again in concordance with study of Jimenez-Nacher et al with mean age of $35 \pm 7$ [mean \pm SD] years. ${ }^{6}$ In this study most common age group was $37-55$ years. Male [49.05\%] and female [52.94\%] were in almost equal proportion in this age group

In this study majority, $75.80 \%$ of the patients were males while only $24.20 \%$ were females. Our findings correlate with two other studies conducted in India which observed $78 \%$ male patients. ${ }^{7}$ However, national data shows that $61 \%$ of the total HIV infected patients are male, which is lower than observed in our study [NACO annual report, 2013-14]. Males are more likely to be infected by HIV because of the greater likelihood of being indulged in promiscuous activities.

In this study, majority, $85.71 \%$ of the study population was literate. [Table 1] $44.29 \%$ of the patients were educated up to primary level. This was in concordance with other study in Indian population in which $41.2 \%$ patients were educated up to primary level. ${ }^{5} \mathrm{~A}$ similar trend was observed in other epidemiological studies ${ }^{8,9}$ In this study, illiteracy rate was almost thrice among female patients [29.41\%] in comparison to male patients [9.44\%]. However, the recently observed changing trend for new HIV infection is more towards less educated groups. ${ }^{9,10}$ Education is important for HIV care, regular clinical visits and better understanding of importance of adherence to ART.

In this study $88.57 \%$ [ $n=62$ ] of the patients were married while $11.42 \%$ were single. Out of $88.57 \%$ of married patients $66.57 \%$ [ $n=46]$ were male.Since majority of patients were married, husband to wife transmission was common among spouses. The problem becomes even worse in a nuclear family where both husband and wife are HIV positive, it has been estimated that the average cost of treatment in the low-income population is $49 \%$ of total household income for a single HIV positive

\begin{tabular}{cccc}
\multicolumn{4}{|c}{$\begin{array}{l}\text { Table 1: Distribution of education status and adherence level in pa- } \\
\text { tients who completed six months of second line art. }\end{array}$} \\
\hline $\begin{array}{c}\text { Education } \\
\text { status }\end{array}$ & $\begin{array}{c}\text { Male } \\
\text { [\% of total } \\
\text { males] }\end{array}$ & $\begin{array}{c}\text { Female } \\
\text { [\% of total } \\
\text { female }]\end{array}$ & $\begin{array}{c}\text { Total } \\
\text { [\% of total } \\
\text { patients }]\end{array}$ \\
\hline Illiterate & $5[9.44 \%]$ & $5[29.41 \%]$ & $10[14.29 \%]$ \\
Primary & $27[50.94 \%]$ & $4[23.53 \%]$ & $31[44.29 \%]$ \\
Secondary & $19[35.84 \%]$ & $7[41.17 \%]$ & $26[37.14 \%]$ \\
College & $2[3.78 \%]$ & $1[5.89 \%]$ & $3[4.28 \%]$ \\
Total & 53 & 17 & 70 \\
\hline
\end{tabular}

Majority of the patients $[\mathrm{n}=60]$ had their mean adherence level $>95 \%$.

\begin{tabular}{cccc}
\hline \multicolumn{3}{c}{ Table 2: Marital status of patients. } \\
\hline $\begin{array}{c}\text { Education status } \\
{[\mathrm{n}=63]}\end{array}$ & Adherence Level Of Patients [Mean \%] \\
\cline { 2 - 4 } & $<80 \%$ & $\mathbf{8 0 - 9 5 \%}$ & $>95 \%$ \\
\hline Illiterate [n=10] & 0 & 1 & 9 \\
Primary[n=26] & 0 & 1 & 25 \\
Secondary[n=24] & 0 & 1 & 23 \\
College[n=3] & 0 & 0 & 3 \\
Total & 0 & 3 & 60 \\
\hline
\end{tabular}

$88.57 \%$ [ $n=62$ ] of patients were married in this study. Out of $88.57 \%$ of married patients $66.57 \%[n=46]$ were male

Table 3: Distribution of the patients based on duration of first line art.

Duration No. of patients $[n=70] \quad$ Percentage of total

$<2$ years $\quad 18 \quad 25.72$

$2-4$ years $\quad 19 \quad 27.14$

$\begin{array}{lll}4-6 \text { years } & 17 & 24.28\end{array}$

6-8 years $\quad 8 \quad 11.42$

$>8$ years $\quad 2 \quad 2.86$

Data not available $\quad 6 \quad 8.58$

$\begin{array}{lll}\text { Total } & 70 & 100\end{array}$


patient which may reach as high as $81 \%$ in advanced stage of disease. Thus, this can cause a great financial burden on a family having more than one HIV positive member.

In this study $11.42 \%$ of the subjects were smokers while $12.85 \%$ had habit of chewing tobacco. Four patients [5.71\%] were habitual or social alcoholics. Several studies were done which shows heavy smoking may predispose to, or increase the risk of OIs in the respiratory tract, and alcohol drinking may hasten disease progression, compromise treatment adherence and may also increase the risk of drug induced hepatotoxicity, the morbidity and mortality rate may be higher in the presence of these habits. ${ }^{11,12,13,14}$
In this study, Out of 70 patients, 16 [22.86\%] had history of $2^{\text {nd }}$ line ART from Private ART clinics and 54 [77.14\%] patients were transferred from other government ART centers. Successful long-term treatment of HIV/ AIDS requires at least $95 \%$ adherence to HAART in order to prevent emergence of drug-resistant HIV variants that lead to regimen failure and limit options for future therapy. Drug cost is a major reason for discontinuation of HAART. ${ }^{15}$ This is particularly important in developing countries like India. The second line ART costs nearly Rs.32, 000 per patient per year as compared to Rs.5000 for first line ART per patient per year, ${ }^{16}$ this much cost of HAART may not be afforded by many Indian patients in private ART clinics.

\begin{tabular}{ccccc} 
Table 4: Utilization pattern of second line art regimens. & & \\
\hline ART regimen & $\begin{array}{c}\text { No of patients } \\
{[n=70]}\end{array}$ & $\begin{array}{c}\text { Percentage of total } \\
\text { patients }\end{array}$ & $\begin{array}{c}\text { No. of encounters with ART } \\
\text { prescription }\end{array}$ & $\begin{array}{c}\text { Percentage of total } \\
\text { encounters }\end{array}$ \\
\hline TDF+3TC+ATV/r & 45 & 64.29 & 264 & 75 \\
D4T+3TC+ATV/r & 15 & 21.42 & 34 & 86.49 \\
AZT+3TC+ATV/r & 6 & 8.57 & 12 & 3.022 \\
AZT+3TC+LPV/r & 2 & 2.86 & 12 & 3.022 \\
ABC+3TC+ATV/r & 2 & 2.86 & 397 \\
Total & 70 & 100 & 100
\end{tabular}

TDF- Tenofovir; D4T- Stavudine; AZT- Zedovudine; 3TC- Lamivudine; ABC-Abacavir, ATV/r-Atazanavir/Ritonavir LPV/r-Lopinavir/Ritonavir

\begin{tabular}{cccc}
\hline Table 5: Treatment substitutions [within second line ART regimens]. & \\
\hline $\begin{array}{c}2^{\text {nd }} \text { line ART regimen before } \\
\text { substitution }\end{array}$ & Specified reason for substitution & $\begin{array}{c}\text { Number of } \\
\text { substitutions }[\mathrm{n}=4]\end{array}$ & $\begin{array}{c}\mathbf{2}^{\text {nd }} \text { line ART regimen after } \\
\text { substitution }\end{array}$ \\
\hline $\begin{array}{c}\text { AZT+3TC+ATV/r } \\
\text { TDF+3TC+ATV/r }\end{array}$ & Anemia & 1 & $\mathrm{D} 4 \mathrm{~T}+3 \mathrm{TC}+\mathrm{ATV} / \mathrm{r}$ \\
$\mathrm{D} 4 \mathrm{~T}+3 \mathrm{TC}+\mathrm{ATV} / \mathrm{R}$ & Hyperbilirubinaemia & 2 & $\mathrm{TDF}+3 \mathrm{TC}+\mathrm{LPV} / \mathrm{r}$ \\
& Lactic acidosis & 1 & $\mathrm{ABC}+3 \mathrm{TC}+\mathrm{ATV} / \mathrm{R}$
\end{tabular}

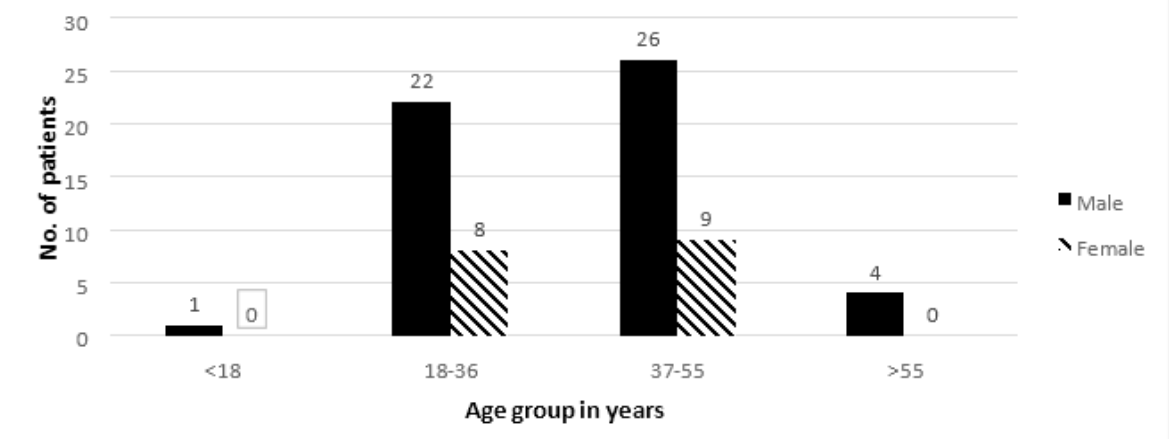

Figure 1: Age and gender distribution of study participants.

\begin{tabular}{cccc} 
Table 6: Treatment hold and restart. & \\
\hline $2^{\text {nd }}$ line ART regimen hold & Reason for treatment hold & $\begin{array}{c}\text { Number of treatment } \\
\text { hold }[\mathrm{n}=1]\end{array}$ & Regimen at restart of treatment \\
\hline AZT+3TC+ATV/R & hyperbilirubinaemia & 1 & AZT+3TC+ATV/R \\
\hline
\end{tabular}


Successful long-term treatment of HIV/AIDS requires at least $95 \%$ adherence to HAART in order to prevent emergence of drug-resistant HIV variants that lead to regimen failure and limit options for future therapy. The barriers to adherence observed in HIV treatment resemble barriers to the successful treatment of other chronic diseases: regimen complexity, side effects resulting in poor tolerability, patient lifestyle factors, and patient-provider relationships. ${ }^{17}$

In this study, $52.86 \%$ of patients were initiated second line ART within 4 years after starting first line ART. Mean time to switching from first line to second line ART was $3.67 \pm 2.29$ years in 63 patients.

While mean time between confirmed HIV diagnosis and start of second line ART was $4.27 \pm 2.84$ years in 70 patients. This type of study was done, which shows median time to switching from first line to second line was 1.81 years in 236 patients from programmers with viral load monitoring. ${ }^{18}$ Another study which was done in India shows similar results to our study. In which the mean duration of treatment with first line ART was $3.15 \pm 1.15$ years. $^{30}$ The durability of first line regimen delays the treatment failure and account for late requirement of second line ART. Major reasons for switching was due to treatment failure, toxicity, adverse drug reactions and poor adherence to first line ART which develops resistance. Our study observed that the average duration of first line ART treatment was higher as compared to other studies.[Table 9] Probably this may be due to an effective first line ART regimen along with good compliance or this may be due to genetic variation according to study population across the world which can give different responses to first line ART.

Out of 70 patients 16 patients had started second line ART at private hospitals. According to NACO, experience had shown that the private sector concurrently uses second-line ART drugs, such as abacavir and PIs as first line, and this has resulted in a cohort of non-naïve treatment experience patients. ${ }^{22}$ Second line ART was started in some patients without following NACO guidelines by various private hospitals with a view to achieve rapid clinical improvement. Few patients were given drug regimens which include both first and second line ART in private hospitals. In such cases second line ART was continued by ART plus center to prevent treatment failure and resistance to drug regimens. Such irrational practice by private hospitals limits treatment options with increasing the chances of drug resistance and mortality. All these factors increases the prevalence of second line ART patients in society.

In this study, 5 second line ART regimens were used. Most common ART regimen prescribed at the initiation of ART was TDF+3TC+ATV/r in $64.29 \%$ patients [Table 4]. This is in accordance with the National guideline which recommends $\mathrm{TDF}+3 \mathrm{TC}+\mathrm{ATV} / \mathrm{r}$ should be preferred as first choice ART regimen. ${ }^{22}$

According to NACO, second-line regimens should include at least three active drugs; one of them from a new class, in order to increase the likelihood of the success of the treatment and to minimize the risk of crossresistance. The PI class should be reserved for second-line treatments. If AZT is used in first-line, NRTI choices in second-line could be TDF. If TDF is used in first-line, NRTI choices could be AZT. If both TDF and AZT can't be used, the last option is $\mathrm{d} 4 \mathrm{~T}$. Thai national guidelines for antiretroviral therapy also suggest that zidovudine [AZT] or Tenofovir [TDF] in combination with lamivudine [3TC] is recommended as the preferred NRTI backbone. ${ }^{23}$ A multi country survey by the WHO found highly variable rates of switching to second-line regimens. ${ }^{24}$ It seems unlikely that this variability is explained by differences in primary resistance to NRTIs or NNRTIs. In another study which was held in Cambodia includes 70 patients, shows that the most frequent second-line regimen used was $\mathrm{ddI}+3 \mathrm{TC}+\mathrm{LPV} / \mathrm{r}[\mathrm{n}=46,65.7 \%]$. Some patients had to be switched to ddI+TDF+LPV/r $[\mathrm{n}=7,10.0 \%]$. The remaining patients were switched to TDF+3TC+LPV/r [n=5, 7.1\%], ddI+AZT+LPV/r [n = $6,8.6 \%]$ or $\mathrm{AZT}+3 \mathrm{TC}+\mathrm{LPV} / \mathrm{r}[\mathrm{n}=2,2.9 \%]$. So, which regimen should

$\begin{gathered}\text { Table 7 : Distribution of patients according level of adherence to } \\
\text { second line art. }\end{gathered}$
\begin{tabular}{ccc}
\hline Level of adherence & No. of encounters [n=397] & Percentage \\
\hline $\mathbf{9 5 \%}$ & 359 & 90.42 \\
$\mathbf{8 0 - 9 5 \%}$ & 24 & 6.04 \\
$\mathbf{< 8 0 \%}$ & 3 & 0.75 \\
Bottle not borrowed & 11 & 2.77 \\
\hline
\end{tabular}

$>95 \%$ : $<3$ doses missed in a period of 30 days; $80-95 \%$ : 3-12 doses missed in a period of 30 days and $<80 \%$ : $>12$ doses missed in a period of 30 days

\begin{tabular}{|c|c|c|}
\hline Opportunistic infection & $\begin{array}{c}\text { Incidence } \\
{[n=52]}\end{array}$ & Percentage incidence \\
\hline $\begin{array}{l}\text { ARI [recurrent respiratory infection] } \\
\text { with }\end{array}$ & 15 & 28.84 \\
\hline Pruritic papular eruptions & 7 & 13.46 \\
\hline Diarrhoea & 7 & 13.46 \\
\hline Candidiasis & 6 & 11.53 \\
\hline Extra pulmonary $\mathrm{TB}$ & 3 & 5.76 \\
\hline UTI & 3 & 5.76 \\
\hline Scabies & 2 & 3.84 \\
\hline Pulmonary TB & 2 & 3.84 \\
\hline Sexually transmitted disease & 1 & 1.92 \\
\hline CMV retinitis & 1 & 1.92 \\
\hline Herpes labialise & 1 & 1.92 \\
\hline Herpes zoster & 1 & 1.92 \\
\hline Perianal dermatitis & 1 & 1.92 \\
\hline Cryptococcal meningitis & 1 & 1.92 \\
\hline CSOM & 1 & 1.92 \\
\hline
\end{tabular}

be use in second line ART depends on the drugs used in first line ART, which can be differ according to genetic variability in HIV prevalent population worldwide. (For drug abbreviations kindly find Table 4)

In this study, most common cause for substituting/hold $2^{\text {nd }}$ line ART regimen was adverse events, recorded in five patients [Table 5(A)(B)]. Out of five patients 2 were substituted from their regimen due to hyperbilirubinemia while in two patients the cause were anemia and lactic acidosis respectively for substitution. One study done in India, which shows 203 patients [16.2\%] developed anemia out of 1256 in which zidovudine was initiated. ${ }^{25}$ The high incidence of Anaemia mandates close monitoring of patients receiving second line ART. Another study of 250 
Modi, et al: Prescription Pattern of Second Line ART

\begin{tabular}{|c|c|c|c|c|c|}
\hline Country & India & Thailand & South Africa & Cambodia & $\begin{array}{c}\text { Me'decins Sans Frontie'res } \\
\text { countries }\end{array}$ \\
\hline Study & $\begin{array}{c}\text { Present } \\
\text { Study } \\
{[\mathrm{n}=70]}\end{array}$ & $\begin{array}{c}\text { Sungkanupa -ph S et } \\
\text { al., } 2007 \\
{[18] \quad[n=98]}\end{array}$ & $\begin{array}{l}\text { Fox MP et al., } \\
\qquad \begin{array}{c}2010^{[19]} \\
{[n=328]}\end{array}\end{array}$ & $\begin{array}{c}\text { Ferradini } \\
\text { L et al., } \\
2011^{[20]} \\
{[\mathrm{n}=70]}\end{array}$ & $\begin{array}{c}\text { Pujades- } \\
\text { Rodrı'guez M } \\
\text { et al., 2008 } \\
{[\mathrm{n}=370]}\end{array}$ \\
\hline $\begin{array}{l}\text { Average duration } \\
\text { on first lineART } \\
\text { [months] }\end{array}$ & 44.04 & 20 & 15.6 & 26.6 & 19.8 \\
\hline
\end{tabular}

patients shows, $41 \%$ [n=102] developed hyperbilirubinemia due to Atazanavir, ${ }^{26}$ which was comparable to $67 \%$ in Rotger $\mathrm{M}$ et al study ${ }^{27}$ and $44 \%$ in Castle study. ${ }^{28}$

High-level adherence to antiretroviral therapy is associated with favorable patient outcomes. ${ }^{29}$ In this study, in majority [90.42\%] of encounters, $>95 \%$ adherence level was reported. [Table 6]. In another clinical study, adherence level of optimal [95-100\%], suboptimal [80-94\%] and poor $[<80 \%]$ was recorded with incidence of $62.9 \%, 28.3 \%$ and $8.8 \%$ patients respectively. Poor $[<80 \%]$ adherence was associated with poor clinical and immunologic response among individuals in this group. ${ }^{29} \mathrm{~A}$ meta-analysis of various second-line ART treatment studies have established the correlation between adherence and successful treatment outcome measured in terms of virological suppression. This meta-analysis showed that adherence of less than $80 \%$ is associated with significantly higher treatment failure rates [383.5/1000 person-years] compared to those with an adherence of more than $95 \%$ [176/1000 person years $[\mathrm{P}<$ $0.001] .{ }^{30}$ The success of any adherence strategy depends on the education of patients before the initiation of ART, an assessment of their understanding of the therapy, and their readiness for treatment. ${ }^{31}$ In our study as shown in Table II majority of the patients were educated who had their mean adherence level $>95 \%[n=60]$. Majority of patients were educated up to primary level [ $n=25]$ followed by secondary level [ $n=23]$.

Co-trimoxazole should be implemented as an integral component of the HIV chronic care package and as a key element of pre antiretroviral therapy care. Co-trimoxazole prophylaxis needs to continue after antiretroviral therapy is initiated until there is evidence of immune recovery. ${ }^{32}$ Co-trimoxazole reduced mortality and the incidence of severe HIV related illnesses in patients with evidence of advanced immune suppression on clinical [WHO stages 3 and 4] or laboratory assessment of CD4 count $<250$ cells $/ \mathrm{mm}^{3}{ }^{33}$

In this study, co-trimoxazole prophylaxis was initiated in $71.42 \%$ patients at the time of initiation of ART. Major cause for not initiating co-trimoxazole prophylaxis was past history of allergic/hypersensitivity reactions to co-trimoxazole. In $28.57 \%$ patients' cotrimoxazole was not initiated. Other studies have reported similar pattern of drug therapy for OIs which mainly included co-trimoxazole [therapeutic dose for PCP] and other antibiotics depending upon the type of infections. ${ }^{34,35,36}$ Inspite of starting co-trimoxazole prophylaxis at start of treatment there were 42 [80.76\%] incidences of OIs in these patients during 6 months of treatment which made role of co-trimoxazole questionable.

Human Immunodeficiency viruses are the initial causative agents in AIDS, but most of the morbidity and mortality in AIDS cases result from opportunistic infections. Identification of such pathogen is very important for clinicians and health planners to tackle the AIDS epidemic in more effective manner. ${ }^{37} \mathrm{HIV}$ causes progressive decrease in immunity making the host vulnerable to number of infectious agents that increase morbidity and mortality in HIV positive individuals. In this study, most common opportunistic infection recorded was ARI [recurrent respiratory tract infection] with $28.54 \%$ incidence. [Table 7]

Other studies carried out in India showed that pulmonary tuberculosis was the most common observed AIDS-defining illness. ${ }^{38,39}$ In another study oral candidiasis [59\%] was found to be the most common opportunistic infection, followed by tuberculosis [56\%], Cryptosporidium infection [47\%]. ${ }^{37}$ Timely diagnosis of TB co-infection is crucial. HIV and Mycobacterium tuberculosis have a synergistic interaction; each accentuates progression of the other. The mortality of HIV-infected patients with TB is comparatively higher than that of HIV-negative TB patients. Anti-tuberculosis treatment is complicated by frequent druginteractions with HAART and adverse drug reactions are more common among HIV-infected patients. ${ }^{40}$

\section{Limitations of the study}

However, like any other study, there were few limitations.

First, it was an observational, single centre study.

Second, the patients were observed for 6 months. Considering the lifelong treatment of ART, long term follow up is necessary.

\section{CONCLUSION}

So, the conclusion of this study is that mean time to switching from first line to second line ART was $3.67 \pm 2.29$ years in 63 patients. Irrational practice by private hospitals limits treatment options with increasing the chances of drug resistance. On the other hand NACO sponsored second line ART was given with a proper treatment protocol which also causes good compliance in patients.

\section{CONFLICTS OF INTEREST}

The authors declare no conflict of interest.

\section{REFERENCES}

1. The Global HIV/AIDS Pandemic, 2006. Available in https://www.cdc.gov/mmwr/ preview/mmwrhtml/mm5531a1.htm [Last accessed on 04-02-2018]

2. Ghate M, Deshpande S, Tripathy S, Nene M, Gedam P, Godbole S, et al. Incidence of common opportunistic infections in HIV-infected individuals in Pune India: analysis by stages of immunosuppression represented by CD4 counts. Int J Infect Dis. 2009;13(1):e1-8.

3. History of HIV and AIDS in UK 1996 onwards. Available in https://www.avert. org/professionals/hiv-around-world/western-central-europe-north-america/uk [last accessed on 04-02-2018]

4. National AIDS Control Organization, Department of AIDS Control. Annual report 2014-15. New Delhi: Department of AIDS Control, National AIDS Control Organization, Ministry of Health \& Family Welfare, Government of India; 2015. 433 p.

5. Sonani HP, Undhad AM, Savani GT. Clinical and socio-demographic profile of patients registered at art centre, SMIMER, Surat. National J Community Med. $2011 ; 2(1): 130-2$

6. Jime'nez-Na'cher I, García B, Barreiro P, Rodriguez-Novoa S, Morello J, 
Gonza'lez-Lahoz J, et al. Trends in the prescription of antiretroviral drugs and impact on plasma HIV-RNA measurements. J Antimicrob Chemother 2008;62(4):816-22

7. Daultani p. Drug utilization and adverse drug reaction monitoring of antiretroviral therapy.[MD thesis] Rajkot, Gujarat :Saurashtra university. 2010.

8. Sharma SK, Dhooria S, Prasad KT, George N, Ranjan S, Gupta D, et al. Outcomes of antiretroviral therapy in a northern Indian urban clinic. Bull World Health Organ. 2010;88(3):222-6.

9. Hargreaves JR, Glynn JR. Educational attainment and HIV-1 infection in developing countries: a systematic review. Trop Med Int Health. 2002;7(6):489-98.

10. Paudel BN, Sharma S, Singh GB, Dhungana GP, Paudel P. Socio-Demographic profile of HIV Patients at Seti Zonal Hospital. J Nepal Health Res Counc. 2008;6(13):107-10

11. Crothers K, Griffith TA, McGinnis KA, Rodriguez-Barradas MC, Leaf DA, Weissman S, et al. The Impact of Cigarette Smoking on Mortality, Quality of Life, and Comorbid IIIness Among HIV-Positive veterans. J Gen Intern Med. 2005;20(12):1142-5

12. Diaz PT, Wewers MD, Pacht E, Drake J, Nagaraja HN, Clanton TL. Respiratory symptoms among HIV-seropositive individuals. Chest. 2003;123(6):1977-82.

13. Hendershot CS, Stoner SA, Pantalone DW, Simoni JM. Alcohol use and antiretroviral adherence: review and meta-analysis. J Acquir Immune Defic Syndr. 2009;52(2):180-202.

14. Chander G, Lau B, Moore RD. Hazardous alcohol use: A risk factor for nonadherence and lack of suppression in HIV infection. J Acquir Immune Defic Syndr. 2006;43(4):411-7.

15. Kiguba R, Byakika-Tusiime J, Karamagi C, Ssali F, Mugyenyi P, Katabira E. Discontinuation and Modification of Highly Active Antiretroviral Therapy in HIV Infected Ugandans Prevalence and Associated Factors. J Acquir Immune Defic Syndr. 2007;45(2):218-23.

16. National AIDS Control Organization, Department of AIDS Control. Care Support \& Treatment: National AIDS Control Programme, Phase-III. New Delhi: Department of AIDS Control, National AIDS Control Organization, Ministry of Health \& Family Welfare, Government of India; $18 \mathrm{p}$.

17. Chesney M. AIDS Patient Care and STDs. 2003;17(4):169-77.

18. Sungkanuparph S, et al. HIV-1 Drug Resistance Mutations Among AntiretroviralNaïve HIV1-Infected Patients in Asia: Results From the TREAT Asia Studies to Evaluate Resistance Monitoring Study. Clin Infect Dis. 2011;52(8):1053-7.

19. Fox MP, Rosen S. Patient retention in antiretroviral therapy programs up to three years on treatment in sub-Saharan Africa, 2007-2009: systematic review. Trop Med Int Health. 2010;15(S1):1-15.

20. Ferradini L, OukV, Segeral O, Nouhin J, Dulioust A, Hak C, et al. High efficacy of lopinavir/r-based second-line antiretroviral treatment after 24 months of follow up at ESTHER/Calmette Hospital in Phnom Penh, Cambodia. J Int AIDS Soc. 2011:14(1):14.

21. Pujades-Rodríguez M, O'Brien D, Humblet $P$, Calmy A. Second-line antiretroviral therapy in resource-limited settings: the experience of Medecins Sans Frontieres. AIDS. 2008;22(11):1305-12.

22. National AIDS Control Organization, Ministry of Health and Family Welfare, Government of India. Antiretroviral Therapy Guidelines for HIV-infected Adults and Adolescents Including Post-exposure Prophylaxis. New Delhi: National AIDS Control Organization, Ministry of Health and Family Welfare, Government of India; 2013 May. p.55-56.

23. Sungkanuparph S, Techasathit W, Utaipiboon C, Chasombat S, Bhakeecheep S, Leechawengwong $\mathrm{M}$, et al. Thai national guidelines for antiretroviral therapy in HIV-1 infected adults and adolescents 2010. Asian Biomedicine. 2010;4:515-28.
24. Renaud-Théry F, Nguimfack BD, Vitoria M, Lee E, Graaff P, Samb B, et al. Use of antiretroviral therapy in resource-limited countries in 2006: distribution and uptake of first- and second-line regimens. AIDS. 2007;21 Suppl 4:S89-95.

25. Agarwal D, Chakravarty J, Chaube L, Rai M, Agrawal NR, Sundar S. High incidence of zidovudine induced anaemia in HIV infected patients in eastern India. Indian J Med Res. 2010;132:386-9.

26. Desai S, Kurli S, Kambar C, Chavala S. Incidence of Atazanavir Induced Hyperbilirubinemia Among HIV/AIDS Patients Taking Second Line ART Drugs. J Basic Appl Sci Res. 2014;4(1):173-8

27. Rotger M, Taffe P, Bleiber G, Gunthard HF, Furrer H, Vernazza P, et al. Swiss HIV Cohort Study. Gilbert syndrome and the development of antiretroviral therapyassociated hyperbilirubinemia. J Infect Dis. 2005;192(8):1381-6.

28. McDonald C, Uy J, Hu W, Wirtz V, Juethner S, Butcher D, et al. Clinical significance of hyperbilirubinemia among HIV-1-infected patients treated with atazanavir/ritonavir through 96 weeks in the CASTLE study. AIDS Patient Care STDS. 2012;26(5):259-64

29. Chi BH, Cantrell RA, Zulu I, Mulenga LB, Levy JW, Tambatamba BC, et al. Adherence to first-line antiretroviral therapy affects non virologic outcomes among patients on treatment for more than 12 months in Lusaka, Zambia. Int J Epidemiol. 2009;38(3):746-56

30. Patel D, Desai M, Shah AN, Dikshit RK. Early outcome of second line antiretroviral therapy in treatment-experienced human immunodeficiency virus positive patients. Perspect Clin Res. 2013;4(4):215-20.

31. WHO. Antiretroviral therapy for HIV infection in adults and adolescents - Recommendations for a public health approach. Geneva: World Health Organization; 2006. p.70-1.

32. WHO. Guidelines on Co-trimoxazole prophylaxis for HIV-related infections among children, adolescents and adults-Recommendations for a public health approach. Geneva: World Health Organization; 2006. P.5

33. National AIDS Control Organization, Ministry of Health and Family Welfare, Government of India. Antiretroviral Therapy Guidelines for HIV-infected Adults and Adolescents Including Post-exposure Prophylaxis. New Delhi: National AIDS Control Organization, Ministry of Health and Family Welfare, Government of India; 2013 May. p.23.

34. Smith DE, Hills DA, Harman C, Hawkins DA, Gazzard BG. Nebulized pentamidine for the prevention of Pneumocystis carinii pneumonia in AIDS patients: experience of 173 patients and a review of the literature. $\mathrm{Q} \mathrm{J}$ Med. 1991;80(291):619-29.

35. Seddon J, Bhagani S. Antimicrobial therapy for the treatment of opportunistic infections in HIV/AIDS patients: a critical appraisal. HIV/AIDS - Res Palliative Care. 2011;3:19-33.

36. HIV Related Opportunistic Infections: Prevention and Treatment. Available in https://aidsinfo.nih.gov/contentfiles/lvguidelines/adult_oi.pdf [Last accessed on 04-02-2018].

37. Singh A, Bairy I, Shivananda PG. Spectrum of opportunistic infections in AIDS cases. Indian J Med Sci. 2003;57(1):16-21

38. Kumarasamy N, Solomon S, Flanigan TP, Hemalatha R, Thyagarajan SP, Mayer $\mathrm{KH}$. Natural History of Human Immunodeficiency Virus Disease in Southern India. Clin Infect Dis. 2003;36(1):79-85.

39. Misra SN, Sengupta D, Satpathy SK. AIDS in India: recent trends in opportunistic infections. Southeast Asian J Trop Med Public Health. 1998;29(2):373-6.

40. Sharma SK, Mohan A, Kadhiravan T. HIV-TB co-infection: Epidemiology, diagnosis and management. Indian J Med Res. 2005:121(4):550-67.

Article History: Submission Date : 01-02-2018; Revised Date : 04-02-2018; Acceptance Date : 07-02-2018.

Cite this article: Modi JP, Kubavat A, Mundhava S, Lalwani U. A Prospective Study to Evaluate Prescription Pattern of Second Line Antiretroviral Therapy Given to HIV Patients. J Young Pharm. 2018;10(1):117-22. 